\title{
The effect of alcohol-containing mouthwash and alcohol-free mouthwash towards the power chains force decay
}

\author{
Willem Santana*, Bergman Thahar**, Endah Mardiati**, Jono Salim** \\ *General Practitioner and Orthodontist, Orthodontics Clinic of Grogol Petamburan, Indonesia \\ ${ }^{* *}$ Departement Of Orthodontics Faculty of Dentistry Universitas Padjadjaran, Indonesia
}

\begin{abstract}
Introduction: Power chains is the common device used in fixed orthodontic treatment. Force decay in power chains is a problem that can affect the teeth movement due to a continuous force cannot be maintained. Force decay in power chain can be affected by the use of alcohol-containing mouthwash or alcohol-free mouthwash. The objective of this study was to determine the effect of alcoholic-containing mouthwash, alcohol-free mouthwash, and artificial saliva towards the power chains force decay. Methods: This research was an experimental analytic laboratory in-vitro with the comparative approach. The sample in this study were 40 power chain, short $A(S A)$; 40 power chain, short $B(S B) ; 40$ power chain, long $A(L A)$; and 40 power chain, long $B(L B)$, which divided into 5 groups that were consecutively exposed to the artificial saliva as control group; Minosep $₫$ with $0.1 \%$ of chlorhexidine gluconate; Listerine $₫$ with $0 \%$ of alcohol; Hexadol ${ }^{\circledR}$ with $9 \%$ of alcohol; and Listerine ${ }^{\circledR}$ with $26.9 \%$ of alcohol. The measurement of force decay was performed with digital force gauge on day $0,1,14$, and 28 . The statistical analysis was done by using the Wilcoxon and Mann-Whitney tests. Result: There was a significant difference $(p<0.05)$ between the force decay of power chain that exposed to the alcohol-containing mouthwash, alcoholfree mouthwash, and the artificial saliva. Conclusion: The force decay level of power chain that exposed to an alcohol-containing mouthwash was higher compared to the force decay level of power chain that exposed to an alcohol-free mouthwash and an artificial saliva.
\end{abstract}

Keywords: Force decay, power chain, alcohol-containing mouthwash, alcohol-free mouthwash, artificial saliva

P-ISSN 1979-0201, e-ISSN 2549-6212 Available from: http://jurnal.unpad.ac.id/pjd/article/view/14476

DOI: 10.24198/pjd.vol29no3.14476

Submission: Jul 2017 Publishing: Nov 2017

\section{INTRODUCTION}

Fixed orthodontic treatment is a treatment to rehabilitate the malocclusion of the teeth by moving the teeth through a force generated from tools such as wire, coil spring, elastic, and synthetic elastomeric materials. Power chain is a synthetic elastomeric material and is a very common tool used in the treatment of fixed orthodontic for canine retracting or closing the space as well as

Corresponding author: Willem Santana, General Practitioner and Orthodontist, Orthodontics Clinic of Grogol Petamburan, Jakarta Indonesia.Email:willem_santana@yahoo.com 
keeping it from reopening the space. Power chains have a polyurethane synthetic polymeric base material containing a chain of urethane chains. Polyurethane rubber synthesized by combining polyester (polyether glycol, and polyhydrocarbons diol) with diisocyanate material. ${ }^{1}$

There are advantages and disadvantages of power chain usage. The advantages include: easy to use, low price, reduce the risk of intraoral trauma, the patient is easy to adapt, relatively hygienic, and available in various sizes and colours. The disadvantages of power chains will diminish in shape over time, absorbing salivary fluids thus affecting their elasticity. ${ }^{2}$

The decline in power chain shape is a problem that can affect the movement of teeth because of light and continuous shape difficult to maintain. As a result of the late teeth movement, as well as the number of patient visits for the activation of the tool will increase. In this regard, many studies have been conducted, such as monitoring the reduction of power chain shape over time, reduction of forces based on different levels of activation, distance of room closure, stretching prior to use, environmental factors, and storage media. ${ }^{2}$

The power chain force decreases rapidly in the first 24 hours by 50 to $70 \%$, then steadily decreases 10 to $20 \%$ for 4 weeks. In dry air, the percentage decrease in force after 21 days by 42 to $63 \%$, otherwise the decrease in force will be greater in moist air or if immersed in water. The results showed that the greatest decrease in force occurred in the first 3 hours and then decreased constantly over the next 21 days. ${ }^{3}$ Another factor that influenced the decrease in power chain shape was the first applied load. The greater the first load applied, the greater the decrease in force. A thermal rotation study on water to create an atmosphere in the mouth suggests a decrease in the lower force in the first 30 minutes by 23 to $37 \%$, after 21 days by 39 to $61 \% .{ }^{4}$

Mouthwash is a common product used in improving oral hygiene. Some of the mouthwashes that were sold on the market containing alcohol and some not. As a product that has antiseptic and antiplaque, mouthwash is always promoted to prevent plaque, caries, gingivitis, and bad breath. A total of $20 \mathrm{ml}$ of mouthwash gargled for 30 seconds in the mouth and then discarded.
This is done twice a day. ${ }^{5}$ Alcohol contained in the mouthwash is ethanol. Alcohol in mouthwash is used as a solvent of various active chemicals and serves as an antiseptic and active ingredient as much as 12 percent. Mouthwashes that are widely sold in the market contain lots of alcohol and who consume most of them are adults. This is according to some researchers allow as the cause of oral cancer. ${ }^{6}$

In the presence of various side effects from the use of an alcohol-containing mouthwash, many health practitioners recommend using alcohol-free mouthwash. Alcohol-free mouthwashes commonly recommended are mouthwashes containing active ingredients such as chlorohexidine gluconate, cetylpyridinium chloride, and essential oils. ${ }^{7}$

Orthodontic treatment in patients often leads to difficulty in maintaining the cleanliness of the mouth, such as frequent plaque stuck, food impurities, and bad breath. Therefore, patients often use mouthwash to maintain oral hygiene. Mouthwashes were commonly used are alcoholcontaining mouthwashes such as Listerine ${ }^{\circledR}$ which has an alcohol content of $26.9 \%$ and an alcohol-free mouthwash containing chlorhexidine gluconate $0.12 \%$. Power chains in contact with alcohol and alcohol-containing mouthwashes will experience a greater force reduction. ${ }^{8}$ The objective of this study was to determine the effect of alcoholcontaining mouthwash, alcohol-free mouthwash, and artificial saliva towards the power chains force decay.

\section{METHODS}

This research was an experimental laboratory analytic research in vitro with a comparative approach. The research was conducted at the Orthodontic Clinic of Dental Hospital of Universitas Padjadjaran and Research Laboratory of Faculty of Mathematics and Natural Science Universitas Padjadjaran. Statistical analysis used non-parametric technique Wilcoxon and MannWhitney test.

Sample in this research were 40 sets of power chain SA (short power chain, from OrthoOrganizer®) with interlink distance 5 eyelet, 40 sets of power chain SB (short power chain, from 3 M Unitek ${ }^{\circledR}$ Power Supply) with interlink distance 5 eyelet, 40 sets of LA (long power chain from 
OrthoOrganizer $®$ ) with 4 eyelet interlink spacings, 40 sets of LB (long power chain from 3 M Unitek $®$ ) with interlink 4 eyelet, Minosep ${ }^{\circledR}$ mouthwash (contain chlorhexidine), Listerine $®$ mouthwash (contain 0\% alcohol), 9\% Hexadol $\circledast$ mouthwash (contain 9\% alcohol), Listerine $\AA$ mouthwash (contain 26.9\% alcohol), and artificial saliva.

The tool used in this research was a square acrylic board measuring $18 \times 5 \times 1 \mathrm{~cm}$ provided as many as 10 pieces, on the board there were 2 pins that are $25 \mathrm{~mm}$ as much as 16 lines and face each other on one line, digital force gauge, stopwatch, plastic storage containers as immersion media, acrylic board support boards, needle holders, ligature cutter, and screwdrivers.

Preparation phase: Power chain SA and SB was cut with 5 eyelet distance, 40 pieces each. LA and LB power chains was cut with 4 eyelets, 40 each. Minosep $\AA$, Listerine $\AA$ with 0 and $26.9 \%$ alcohol, Hexadol $($, respectively, were poured into $150 \mathrm{ml}$ immersion baths. Artificial saliva was provided in five groups. Stopwatch was used to measure the immersion time and force gauge was provided to measure the power chain shape.

An acrylic board with 10 ready-made pin boards, divided into five groups: Group I was a control group, two acrylic boards (board A setting for eight SA and eight SB power chains, board $B$ setting for eight LA and eight LB power chains) will be immersed into artificial saliva. Group II was two acrylic boards (Board $C$ setting for eight SA and eight SB power chains, board D setting for 8 LA and eight LB power chains) to be immersed in Minosep mouthwash. Group III was two acrylic boards (Board E setting for eight SA and eight SB power chains, Board $F$ setting for eight LA and eight LB power chains) to be immersed in Listerine mouthwash. Group IV was two acrylic boards
(Board G setting for eight SA and eight SB power chains, board $\mathrm{H}$ setting for eight $\mathrm{LA}$ and eight LB power chains) to be immersed into Hexadol ${ }^{\circledR}$ mouthwash. Group V was two acrylic board (Board I setting for eight SA and eight SB power chains, board $\mathrm{J}$ setting for eight LA and 8 LB power chain) to be immersed into Listerine $₫$ mouthwash with 26.9\% alcohol.

Early chain power shape measurement stage: Short power chain with 5 eyelet distance, mounted on each acrylic board with a pin. The long power chain with a distance of 4 eyelets, mounted on each acrylic board (Fig. 1). Initial force measurements on power chain samples were performed on day 0 with force gauge. Measurement mode: the power chain edge on one side of the pin is attached to the force gauge link and was measured in terms of shape and then attaches again to the pin (Fig. 1).

Immersion stage. After the initial power chain measurement was finished, proceed to the immersion stage. Group 1 as a control group was immersed in artificial saliva. Group II was immersed into Minosep ${ }^{\circledR}$ mouthwash with a concentration of $0.1 \%$ chlorhexidine gluconate. Immersion in mouthwash was done twice a day every 12 hours according to the mouth rinse.

The length of immersion in each mouthwash was 30 seconds measured using a stopwatch. After immersion, the Group II board was removed and then immersed in an artificial saliva separate from Group I. This was done for 28 days following the procedure as above. Group III was immersed in Listerine ${ }^{\circ}$ mouthwash with a $0 \%$ alcohol concentration. The immersion procedure was the same as that done in Group II. Group IV was immersed into Hexadol $\circledast$ mouthwash with $9 \%$ alcoholic concentration. The immersion procedure

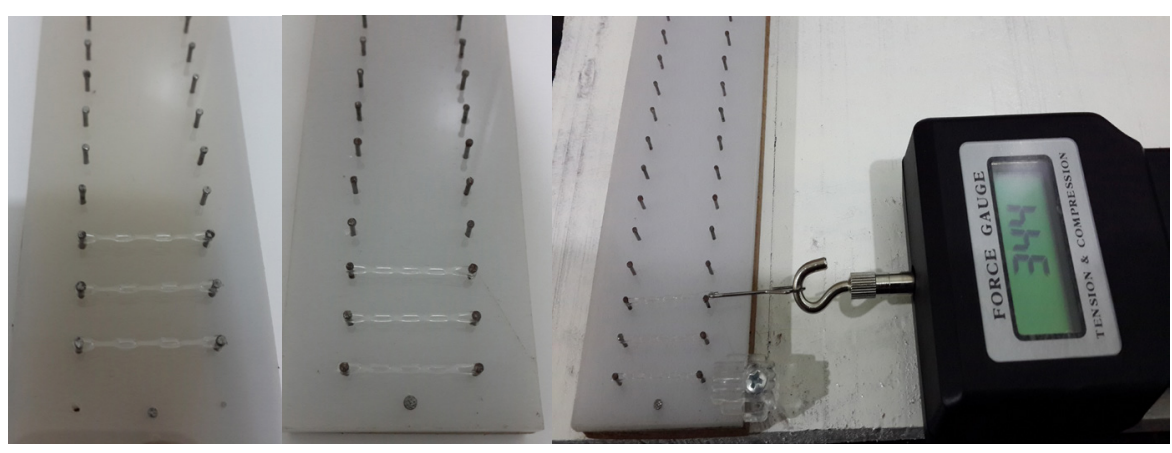

Figure 1. Power chain force measurement with the force gauge 
was the same as that done in Groups II and III. Group V was immersed into Listerine mouthwash with an alcohol concentration of $26.9 \%$. The immersion procedure was the same as done in Groups II, III and IV. After the immersion stage, each group was placed in a container and stored in an incubator with a constant temperature of $37^{\circ} \mathrm{C}$.

Measurement stages of power chain decrease. Measurement of force drop was done on each group with force gauge. Measurement of the force drop was done three times on the $1^{\text {st }}$, $14^{\text {th }}$, and $28^{\text {th }}$ days. After the measurement of the shape drop was completed, the power chain in the acrylic board was re-stored in the incubator.

\section{RESULTS}

The results were analyzed by Wilcoxon and MannWhitney test with $p<0.05$. The results of the study as follows:

Table 1 shows the largest percentage of power-chain power loss was the LA power chain. The smallest power chain decrease percentage was the SB power chain. The biggest percentage reduction of power chain shape was LA power chain

Table 1. The percentage average of the force decay $(\%)$ and the remaining force of the power chain (gr) immersed in the artificial saliva

\begin{tabular}{ccccc}
\hline \multirow{2}{*}{$\begin{array}{c}\text { Power } \\
\text { Chain }\end{array}$} & HO & \multicolumn{3}{c}{ Artificial saliva } \\
\cline { 3 - 5 } & & D1 & D14 & D28 \\
\hline \multirow{2}{*}{ SA } & $100 \%$ & $46.3 \%$ & $59.3 \%$ & $65.2 \%$ \\
& $360.12 \pm 6 \mathrm{gr}$ & $193.25 \pm 3.9 \mathrm{gr}$ & $146.38 \pm 3 \mathrm{gr}$ & $125.25 \pm 2.8 \mathrm{gr}$ \\
SB & $100 \%$ & $32.2 \%$ & $42.5 \%$ & $45.9 \%$ \\
& $381.75 \pm 6.5 \mathrm{gr}$ & $258.75 \pm 4.3 \mathrm{gr}$ & $219.62 \pm 3.6 \mathrm{gr}$ & $206.38 \pm 3.5 \mathrm{gr}$ \\
LA & $100 \%$ & $47.7 \%$ & $62.1 \%$ & $67.9 \%$ \\
& $343 \pm 2.7 \mathrm{gr}$ & $179.38 \pm 4.9 \mathrm{gr}$ & $130.12 \pm 3.8 \mathrm{gr}$ & $110.25 \pm 4.2 \mathrm{gr}$ \\
LB & $100 \%$ & $39.8 \%$ & $50.3 \%$ & $55.2 \%$ \\
& $363.38 \pm 2.2 \mathrm{gr}$ & $218.88 \pm 4.1 \mathrm{gr}$ & $180.62 \pm 2.4 \mathrm{gr}$ & $162.88 \pm 3 \mathrm{gr}$ \\
\hline
\end{tabular}

Table 2. The percentage average of the force decay (\%) and the remaining force of the power chain (gr) immersed in Minosep ${ }^{\circledR}$ on day $0,1,14$, dan 28

\begin{tabular}{ccccc}
\hline \multirow{2}{*}{$\begin{array}{c}\text { Power } \\
\text { Chain }\end{array}$} & HO & \multicolumn{3}{c}{ Minosep® mouthwash } \\
\cline { 2 - 5 } & & D1 & D14 & D28 \\
\hline \multirow{2}{*}{ SA } & $100 \%$ & $46.8 \%$ & $59.7 \%$ & $65.3 \%$ \\
& $363.50 \pm 5.6 \mathrm{gr}$ & $193.25 \pm 3.0 \mathrm{gr}$ & $146.50 \pm 3 \mathrm{gr}$ & $126.00 \pm 2.7 \mathrm{gr}$ \\
SB & $100 \%$ & $32.4 \%$ & $42.6 \%$ & $46.1 \%$ \\
& $382.50 \pm 4.8 \mathrm{gr}$ & $258.38 \pm 3.0 \mathrm{gr}$ & $219.38 \pm 2.4 \mathrm{gr}$ & $206.25 \pm 3.6 \mathrm{gr}$ \\
LA & $100 \%$ & $47.6 \%$ & $62.3 \%$ & $68.3 \%$ \\
& $344.00 \pm 3.1 \mathrm{gr}$ & $180.38 \pm 2.8 \mathrm{gr}$ & $129.75 \pm 3.0 \mathrm{gr}$ & $108.88 \pm 3.0 \mathrm{gr}$ \\
LB & $100 \%$ & $40.3 \%$ & $50.4 \%$ & $55.3 \%$ \\
& $364.25 \pm 3.9 \mathrm{gr}$ & $217.62 \pm 3.7 \mathrm{gr}$ & $180.75 \pm 1.7 \mathrm{gr}$ & $162.75 \pm 3.4 \mathrm{gr}$ \\
\hline
\end{tabular}

Table 3. The percentage average of the force decay (\%) and the remaining force of the power chain (gr) immersed in Listerine ${ }^{\circledR}$ with $0 \%$ alcohol on day $0,1,14$, dan 28

\begin{tabular}{ccccc}
\hline \multirow{2}{*}{$\begin{array}{c}\text { Power } \\
\text { Chain }\end{array}$} & HO & \multicolumn{3}{c}{ Listerine ${ }^{\circledR}$ with 0\% alcohol } \\
\cline { 3 - 5 } & & D1 & D14 & D28 \\
\hline \multirow{2}{*}{ SA } & $100 \%$ & $46.2 \%$ & $59.4 \%$ & $64.9 \%$ \\
& $358.12 \pm 6.6 \mathrm{gr}$ & $192.63 \pm 4.4 \mathrm{gr}$ & $145.50 \pm 2.4 \mathrm{gr}$ & $125.62 \pm 2.6 \mathrm{gr}$ \\
\multirow{2}{*}{ SB } & $100 \%$ & $32.6 \%$ & $42.8 \%$ & $46.1 \%$ \\
& $383.25 \pm 3.7 \mathrm{gr}$ & $258.50 \pm 3.5 \mathrm{gr}$ & $219.25 \pm 3.4 \mathrm{gr}$ & $206.62 \pm 3.6 \mathrm{gr}$ \\
& $100 \%$ & $47.9 \%$ & $62.1 \%$ & $68.5 \%$ \\
LA & $343.38 \pm 2.6 \mathrm{gr}$ & $178.88 \pm 3.3 \mathrm{gr}$ & $130.00 \pm 3.3 \mathrm{gr}$ & $108.12 \pm 4.0 \mathrm{gr}$ \\
& $100 \%$ & $40.5 \%$ & $50.4 \%$ & $55.4 \%$ \\
LB & $364.62 \pm 3.4 \mathrm{gr}$ & $217.00 \pm 3.0 \mathrm{gr}$ & $180.75 \pm 2.7 \mathrm{gr}$ & $162.62 \pm 3.4 \mathrm{gr}$ \\
\hline
\end{tabular}


by $47.6 \%(180.38 \pm 2.8 \mathrm{gr})$ at day $1,62.3 \%(129.75$ $\pm 3.0 \mathrm{gr})$ at day 14 , and $68.3 \%(108.88 \pm 3.0 \mathrm{gr})$ at day 28. The smallest power chain decline percentage was the power chain SB of $32.4 \%(258.38 \pm 3.0$ gr) at day $1,42.6 \%(219.38 \pm 2.4$ gr $)$ at day 14 , and $46.1 \%(206.25 \pm 3.6 \mathrm{gr})$ at day 28 (Table 2).

The largest percentage reduction of power chain shape was LA power chain at $47.9 \%$ $(178.88 \pm 3.3 \mathrm{gr})$ at day $1,62.1 \%(130.00 \pm 3.3 \mathrm{gr})$ day $14,68.5 \%(108.12 \pm 4.0 \mathrm{gr})$ at day 28 . The smallest power chain decline percentage was the power chain SB of $32.6 \%(258.50 \pm 3.5$ gr) at day $1,42.8 \%$ $(219.25 \pm 3.4 \mathrm{gr})$ at day $14,46.1 \%(206.62 \pm 3.6 \mathrm{gr})$ at day 28 (Table 3).

The largest percentage reduction in power chain shape was the LA power chain of $52.6 \%$ $(163.50 \pm 3.0 \mathrm{gr})$ at day $1,66.2 \%(116.38 \pm 2.0 \mathrm{gr})$ at day $14,71.5 \%(98.12 \pm 2.8 \mathrm{gr})$ at day 28 . The smallest power chain decline percentage was the power chain SB of $37.8 \%(238.50 \pm 4.1 \mathrm{gr})$ at day 1 , $47.9 \%(199.50 \pm 3.1 \mathrm{gr})$ at day $14,51.8 \%(184.75 \pm 3.2$ gr) at day 28 (Table 4).
The largest percentage reduction of power chain shape was LA power chain of $56.4 \%$ (150.25 \pm $5.0 \mathrm{gr})$ at day $1,70.0 \%(103.75 \pm 3.1 \mathrm{gr})$ at day $14,75.9 \%(83.00 \pm 2.8 \mathrm{gr})$ at day 28 . The smallest power chain decline percentage was the power chain SB of $40.7 \%(226.50 \pm 1.6$ gr) at day $1,51.3 \%$ $(186.00 \pm 2.4 \mathrm{gr})$ at day $14,55.8 \%(168.87 \pm 2.2 \mathrm{gr})$ at day 28 (Table 5 ).

With the $p$-value $<0.05$ means that comparison between the power chain of $L A$, LB, SA, and SB immersed with artificial saliva, Minosep $\AA$, Listerine $₫$ with 0 and $26.9 \%$ alcohol, Hexadol $\circledast$ on days 1,14 , and 28 was significant. It can be seen in Table 6 .

The result of Mann-Whitney statistical analysis test was obtained by comparison value of power chain force of LA, LB, SA, and SB soaked in artificial saliva, Minosep $\AA$, Listerine $\AA 0 \%$, Hexadol $\circledast 9 \%$, Listerine $\circledast 26,9 \%$ on day 1,14 and 28 were 0.001 . It means that the $p$-value was $<0.05$, so the test has significant differences (Table 6).

Table 4. The percentage average of the force decay (\%) and the remaining force of the power chain (gr) immersed in Hexadol $\circledast$ with $9 \%$ alcohol on day $0,1,14$ dan 28

\begin{tabular}{ccccc}
\hline \multirow{2}{*}{$\begin{array}{c}\text { Power } \\
\text { Chain }\end{array}$} & HO & \multicolumn{3}{c}{ Hexadol $®$ with 9\% alcohol } \\
\cline { 3 - 5 } & $100 \%$ & $51.1 \%$ & D14 & D28 \\
\hline \multirow{2}{*}{ SA } & $361.88 \pm 4.3 \mathrm{gr}$ & $177.00 \pm 2.8 \mathrm{gr}$ & $136.00 \pm 1.7 \mathrm{gr}$ & $114.25 \pm 2.5 \mathrm{gr}$ \\
& $100 \%$ & $37.8 \%$ & $47.9 \%$ & $51.8 \%$ \\
SB & $383.50 \pm 5.1 \mathrm{gr}$ & $238.50 \pm 4.1 \mathrm{gr}$ & $199.50 \pm 3.1 \mathrm{gr}$ & $184.75 \pm 3.2 \mathrm{gr}$ \\
& $100 \%$ & $52.6 \%$ & $66.2 \%$ & $71.5 \%$ \\
LA & $344.62 \pm 2.9 \mathrm{gr}$ & $163.50 \pm 3.0 \mathrm{gr}$ & $116.38 \pm 2.0 \mathrm{gr}$ & $98.12 \pm 2.8 \mathrm{gr}$ \\
& $100 \%$ & $46.3 \%$ & $55.0 \%$ & $60.2 \%$ \\
LB & $365.12 \pm 3.2 \mathrm{gr}$ & $196.13 \pm 4.0 \mathrm{gr}$ & $164.25 \pm 3.2 \mathrm{gr}$ & $145.38 \pm 3.0 \mathrm{gr}$ \\
\hline
\end{tabular}

Table 5. The percentage average of the force decay (\%) and the remaining force of the power chain (gr) immersed in Listerine ${ }^{\circledR}$ with $26.9 \%$ alcohol on day $0,1,14$, dan 28

\begin{tabular}{ccccc}
\hline \multirow{2}{*}{$\begin{array}{c}\text { Power } \\
\text { Chain }\end{array}$} & HO & \multicolumn{3}{c}{ Listerine ${ }^{\circ}$ with $26.9 \%$ alcoho } \\
\cline { 3 - 5 } & $100 \%$ & $54.7 \%$ & D14 & D28 \\
\hline \multirow{2}{*}{ SA } & $359.38 \pm 5.4 \mathrm{gr}$ & $162.88 \pm 2.9 \mathrm{gr}$ & $125.25 \pm 2.7 \mathrm{gr}$ & $100.13 \pm 2.0 \mathrm{gr}$ \\
& $100 \%$ & $40.7 \%$ & $51.3 \%$ & $55.8 \%$ \\
SB & $382.25 \pm 3.0 \mathrm{gr}$ & $226.50 \pm 1.6 \mathrm{gr}$ & $186.00 \pm 2.4 \mathrm{gr}$ & $168.87 \pm 2.2 \mathrm{gr}$ \\
& $100 \%$ & $56.4 \%$ & $70.0 \%$ & $75.9 \%$ \\
LA & $345.00 \pm 3.2 \mathrm{gr}$ & $150.25 \pm 5.0 \mathrm{gr}$ & $103.75 \pm 3.1 \mathrm{gr}$ & $83.00 \pm 2.8 \mathrm{gr}$ \\
& $100 \%$ & $49.3 \%$ & $58.8 \%$ & $64.5 \%$ \\
LB & $363.88 \pm 3.1 \mathrm{gr}$ & $184.62 \pm 4.0 \mathrm{gr}$ & $149.88 \pm 2.1 \mathrm{gr}$ & $129.12 \pm 2.2 \mathrm{gr}$ \\
\hline
\end{tabular}


Table 6 . The power chain force decay comparison analysis

\begin{tabular}{|c|c|c|c|c|c|}
\hline \multicolumn{6}{|c|}{ The force decay comparison analysis of the power chain LA } \\
\hline Immersion solution & $\mathrm{n}$ & $\bar{X} \bar{X}(\mathrm{SD})$ & $\mathrm{p}$-value D1 & p-value D14 & p-value D28 \\
\hline Saliva-Minosep $®$ & 8 & $180.1 \pm 3.8$ & $0.866^{\circ}$ & $1.000^{\circ}$ & $0.302^{\circ}$ \\
\hline Saliva-Listerine $® 0 \%$ & 8 & $178.5 \pm 4.0$ & $0.866^{\circ}$ & $0.944^{\circ}$ & $0.182^{\circ}$ \\
\hline Saliva-Hexadol $\circledast 9 \%$ & 8 & $171.4 \pm 3.9$ & $0.012^{*}$ & $0.012^{*}$ & $0.011^{*}$ \\
\hline Saliva-Listerine ${ }^{2} 26.9 \%$ & 8 & $164.9 \pm 4.9$ & $0.012^{*}$ & $0.012^{*}$ & $0.012^{*}$ \\
\hline $\begin{array}{l}\text { Hexadol } \circledast 9 \% \text {-Listerine } \AA \\
26.9 \%\end{array}$ & 8 & $156.9 \pm 2.5$ & $0.012^{*}$ & $0.012^{*}$ & $0.011^{*}$ \\
\hline \multicolumn{6}{|c|}{ The force decay comparison analysis of the power chain SA } \\
\hline Immersion solution & $\mathrm{n}$ & $\bar{X} \bar{X}(\mathrm{SD})$ & $\mathrm{p}$-value $\mathrm{D} 1$ & p-value D14 & p-value D28 \\
\hline Saliva-Minosep $®$ & 8 & $218.25 \pm 3.85$ & $0.497^{\circ}$ & $0.723^{\circ}$ & $0.888^{\circ}$ \\
\hline Saliva-Listerine $® 0 \%$ & 8 & $218.75 \pm 3.5$ & $0.441^{\circ}$ & $0.864^{\circ}$ & $0.786^{\circ}$ \\
\hline Saliva-Hexadol $\circledast 9 \%$ & 8 & $207.50 \pm 4.0$ & $0.012^{*}$ & $0.012^{*}$ & $0.012^{*}$ \\
\hline Saliva-Listerine ${ }^{2} 26.9 \%$ & 8 & $201.75 \pm 4.0$ & $0.012^{*}$ & $0.012^{*}$ & $0.011^{*}$ \\
\hline $\begin{array}{l}\text { Hexadol } \circledast 9 \% \text {-Listerine } ® \\
26.9 \%\end{array}$ & 8 & $190.35 \pm 4.0$ & $0.017^{*}$ & $0.012^{*}$ & $0.011^{*}$ \\
\hline \multicolumn{6}{|c|}{ The force decay comparison analysis of the power chain LA and LB } \\
\hline Immersion solution & $\mathrm{n}$ & $\bar{X} \bar{X}(\mathrm{SD})$ & $\mathrm{p}$-value D1 & p-value D14 & p-value D28 \\
\hline Saliva-Minosep $®$ & 8 & $193.30 \pm 3.5$ & $0.888^{\circ}$ & $0.752^{\circ}$ & $0.482^{\circ}$ \\
\hline Saliva-Listerine $® 0 \%$ & 8 & $192.90 \pm 4.1$ & $0.777^{\circ}$ & $0.276^{\circ}$ & $0.671^{\circ}$ \\
\hline Saliva-Hexadol $\circledast 9 \%$ & 8 & $185.15 \pm 3.4$ & $0.011^{*}$ & $0.012^{*}$ & $0.012^{*}$ \\
\hline Saliva-Listerine ${ }^{\circledR} 26.9 \%$ & 8 & $178.10 \pm 3.4$ & $0.012^{*}$ & $0.011^{*}$ & $0.011^{*}$ \\
\hline Saliva-Listerine ${ }^{2} 26.9 \%$ & 8 & $170.30 \pm 2.8$ & $0.011^{*}$ & $0.011^{*}$ & $0.012^{*}$ \\
\hline $\begin{array}{l}\text { Hexadol } \circledast 9 \% \text {-Listerine } ® \\
26.9 \%\end{array}$ & 8 & $193.30 \pm 3.5$ & $0.888^{\circ}$ & $0.752^{\circ}$ & $0.482^{\circ}$ \\
\hline \multicolumn{6}{|c|}{ The force decay comparison analysis of the power chain SA and SB } \\
\hline Immersion solution & $\mathrm{n}$ & $\bar{X} \bar{X}(\mathrm{SD})$ & $\mathrm{p}$-value D1 & p-value D14 & p-value D28 \\
\hline Saliva-Minosep ${ }^{\circledR}$ & 8 & $258.55 \pm 3.7$ & $0.944^{\circ}$ & $0.547^{\circ}$ & $1.000^{\circ}$ \\
\hline Saliva-Listerine $® 0 \%$ & 8 & $258.60 \pm 3.9$ & $1.000^{\circ}$ & $0.725^{\circ}$ & $0.799^{\circ}$ \\
\hline Saliva-Hexadol $\circledast 9 \%$ & 8 & $248.60 \pm 4.3$ & $0.012^{*}$ & $0.011^{*}$ & $0.012^{*}$ \\
\hline Saliva-Listerine $® 26.9 \%$ & 8 & $242.52 \pm 2.9$ & $0.012^{*}$ & $0.012^{*}$ & $0.011^{*}$ \\
\hline $\begin{array}{l}\text { Hexadol } \circledast 9 \% \text {-Listerine } \circledast \\
26.9 \%\end{array}$ & 8 & $232.50 \pm 2.8$ & $0.011^{*}$ & $0.011^{*}$ & $0.012^{*}$ \\
\hline \multicolumn{6}{|c|}{ The force decay comparison analysis of the power chain LA and LB } \\
\hline Immersion solution & $\mathrm{n}$ & $\bar{X} \bar{X}(\mathrm{SD})$ & $\mathrm{p}$-value $\mathrm{D} 1$ & p-value D14 & p-value D28 \\
\hline Artificial Saliva & 16 & $0.001^{*}$ & $0.001^{*}$ & $0.001^{*}$ & $\mathrm{~S}$ \\
\hline Minosep ${ }^{\circledR}$ & 16 & $0.001^{*}$ & $0.001^{*}$ & $0.001^{*}$ & M \\
\hline Listerine $® 0 \%$ & 16 & $0.001^{*}$ & $0.001^{*}$ & $0.001^{*}$ & L $0 \%$ \\
\hline Hexadol $\circledast 9 \%$ & 16 & $0.001^{*}$ & $0.001^{*}$ & $0.001^{*}$ & $\mathrm{H} 9 \%$ \\
\hline Listerine $® 26.9 \%$ & 16 & $0.001^{*}$ & $0.001^{*}$ & $0.001^{*}$ & L 26.9\% \\
\hline \multicolumn{6}{|c|}{ The force decay comparison analysis of the power chain SA and SB } \\
\hline Immersion solution & $\mathrm{n}$ & $\bar{X} \bar{X}(\mathrm{SD})$ & $\mathrm{p}$-value D1 & p-value D14 & p-value D28 \\
\hline Artificial Saliva & 16 & $0.001^{*}$ & $0.001^{*}$ & $0.001^{*}$ & $\mathrm{~S}$ \\
\hline Minosep $®$ & 16 & $0.001^{*}$ & $0.001^{*}$ & $0.001^{*}$ & M \\
\hline Listerine $® 0 \%$ & 16 & $0.001^{*}$ & $0.001^{*}$ & $0.001^{*}$ & L 0\% \\
\hline Hexadol@ 9\% & 16 & $0.001^{*}$ & $0.001^{*}$ & $0.001^{*}$ & H 9\% \\
\hline Listerine $® 26.9 \%$ & 16 & $0.001^{*}$ & $0.001^{*}$ & $0.001^{*}$ & L 26.9\% \\
\hline
\end{tabular}

\section{DISCUSSION}

In this research, there was a huge difference in the force between LA, LB, SA, and SB power chains and there was a difference in power chain shape that were in contact with artificial saliva, alcohol-free mouthwash, and alcohol-containing mouthwash. All power chains used in this study decreased in shape over time and were unable to produce constant force. ${ }^{9}$ 
The results of the research on day 0 showed that all of the power chains were still elastic and produce a great force. The power chain force decreases continuously, the measurement of force on the $1^{\text {st }}$ day showed the greatest decrease, followed by the $14^{\text {th }}$ day shape measurement of a decrease in force with the remaining force smaller than the $1^{\text {st }}$ day. Measurements on day 28 showed the smallest remaining forces and reduced power chain state of elasticity.

The greatest decrease in power chain force was treated by artificial saliva, alcohol-containing mouthwash, and alcohol-free mouthwash on day 1 , with a $40-50 \%$ reduction in force. On the $28^{\text {th }}$ day, the average power chain force remaining is between $30-40 \%$. The power chain LA on day 1 experienced the greatest shape decline between $47-55 \%$. The power chain SB on the $1^{\text {st }}$ day experienced the smallest shape decrease between $32-37 \%$ and the force remaining on day 28 was between $45-55 \%$. The decline of power chain shape began to stabilize around 10-15\% between day 1 and day 14, between day 14 and day 28 about 5-9\%.

Comparisons of power chain LA, LB, SA, and $S B$ shapes in contact with control saliva and alcoholfree mouthwash (Minosep $₫$ and Listerine $₫ 0 \%$ ) on days 1,14 and 28 had no significant difference $(p>0.05)$. The comparison of power chain shapes LA, LB, SA, and SB in contact with control saliva and alcohol-containing mouthwash (Hexadol ${ }^{\circledR}$ 9\% and Listerine ${ }^{\circledR} 26.9 \%$ ) at days 1, 14 and 28 had significant differences $(p<0.05)$. The power chains that come into contact with an alcohol-containing mouthwash will decrease in a larger force when compared to those in contact with artificial saliva and alcohol-free mouthwash. Alcohol (ethanol) with chemical formula $\mathrm{CH}_{3}-\mathrm{CH}_{2}-\mathrm{OH}$ contained in mouthwash binds to polyurethane polymer bonds in power chain. ${ }^{8}$

The comparison of power chain shapes LA, LB, SA, and SB in contact with Hexadol ${ }^{\circledR} 9 \%$ and Listerine ${ }^{\circledR} 26.9 \%$ on days 1,14 and 28 had significant differences $(p<0.05)$. The results showed that the contact power chain with listerine with an alcohol concentration of $26.9 \%$ decreased the force greater than the power chain that was in contact with the alcohol Hexadol $₫ 9 \%$ concentration.

The results of comparative studies of the power chain LA and LB decline, the comparison of $S A$ and SB power-chain shapes showed that on days 1, 14, and 28, LB and SB power chains have larger rest shapes and a smaller percentage decrease in force from power chains LA and SA. Statistical analysis showed a significant difference $(p<0.05)$. Patients receiving orthodontic treatment may be advised to use non-alcohol mouthwash to maintain oral hygiene. Orthodontists can be more selective and careful in choosing the type and brand of power chain to be used for orthodontic treatment.

\section{CONCLUSION}

The force decay level of power chain that exposed to an alcohol-containing mouthwash was higher compared to the force decay level of power chain that exposed to an alcohol-free mouthwash and an artificial saliva.

\section{REFERENCES}

1. Singh VP, Pokhrael PR, Pariekh K, Singh VP. Elastics in Orthodontics: A Review. Health Rennaissance 2012;10(1):49-56. DOI: 10.3126/ hren.v10i1.6008.

2. Buchmann N, Senn C, Ball J, Brauchli L. Influence of initial strain on the force decay of curently available elastic chains over time. Angle Orthod. May 2012;82(3): p. 529-35. DOI: 10.2319/062011-399.1.

3. Lu TC, Wang WN, Tarng TH, Chen JW. Force decay of elastomeric chain-a serial study. Part II. Am J Orthod Dentofacial Orthop Oct 1993;104(4):373-7. DOI: $10.1016 /$ S08895406(05)81336-8.

4. De Genova DC, McInnes-Ledoux P, Weinberg $R$, Shaye R. Force Degradation of orthodontic elastomeric chains: a product comparison study. Am J Orthod May 1985;87(5):377-84.

5. Anyanwu OC, Baugh KK, Bennett SB, Johnson JM, Madlock RL, Pollard NE, et al. Comparison of the antibacterial effectiveness of alcoholcontaining and non-alcohol-containing mouthwashes. J Sci 2011;2:7-12.

6. De Blanc SAL, Baruzzi AM. Mouthrinses containing alcohol and oral cancer. revision of epidemiological studies. Braz Oral Res 2007;21(spe):16-22. DOI: 10.1590/S180683242007000500004 . 
7. De Paola LG, Spolarich AE. Safety and efficacy of antimicrobial mouthrinses in clinical practice. J Dent Hyg 2007;81(suppl 1):117.

8. Larrabee TM, Liu SS, Torres-Gorena A, SotoRojas A, Eckert GJ, Stewart KT. The effects of varying alcohol concentrations commonly found in mouth rinses on the force decay of elastomeric chain. Angle Orthod Sep 2012;82(5):894-9. DOI: 10.2319/062211-407.1.

9. Baty DL, Storie DJ, von Fraunhofer JA. Synthetic elastomeric chains: a literature review. Am J Orthod Dentofacial Orthop Jun 1994;105(6):536-42. DOI: 10.1016/S08895406(94)70137-7. 